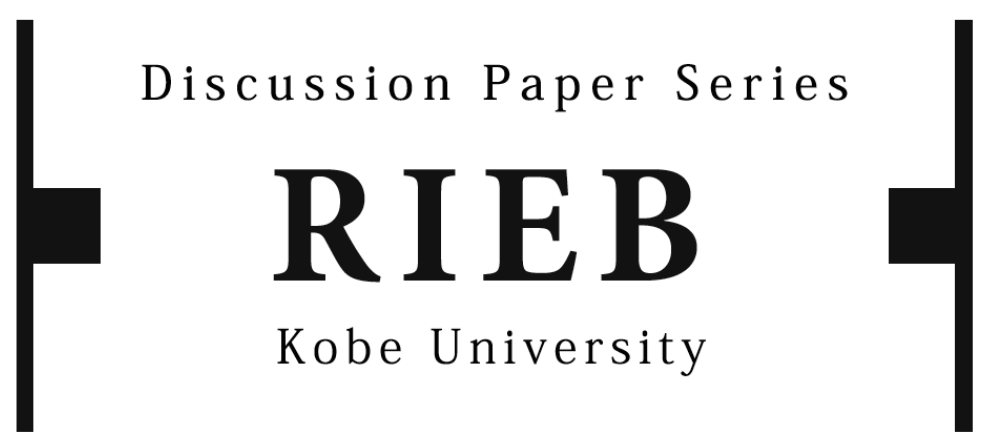

DP2014-20

An Experimental Examination of Compensation Schemes and Level of Effort in Differentiated Tasks

\author{
Hiromasa TAKAHASHI \\ Junyi SHEN \\ Kazuhito OGAWA
}

May 13, 2014

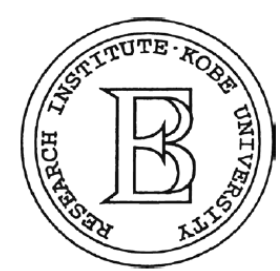

Research Institute for Economics and Business Administration

Kobe University

2-1 Rokkodai, Nada, Kobe 657-8501 JAPAN 


\title{
AN EXPERIMENTAL EXAMINATION OF COMPENSATION SCHEMES AND LEVEL OF EFFORT IN DIFFERENTIATED TASKS
}

\author{
Hiromasa Takahashi *, Junyi Shen †, and Kazuhito Ogawa^ \\ *Faculty of International Studies, Hiroshima City University, Japan, \\ †Research Institute for Economics and Business Administration, Kobe University, \\ Japan, \\ and ^Faculty of Sociology, Kansai University, Japan
}

\begin{abstract}
We examine the influence of different compensation schemes on exertion of effort for differentiated tasks. The first type of task is assumed to be boring and has no intrinsic motivation, while the second is assumed to be interesting, and has a higher intrinsic motivation. The results are as follows: (1) in the first task, standard economic theory, which claims higher pay should result in higher effort, does not hold. (2) Standard economic theory holds for the second task, which predicts that the higher the incentive, the more effort one exerts, and achieves a higher performance on average.
\end{abstract}

Keywords: real effort experiment, intrinsic motivation, loss aversion, fixed pay, incentive pay

JEL classification: M52, J33

\section{INTRODUCTION}

According to standard economic theory, the more monetary incentive is provided, the more effort one exerts, achieving a higher performance on average. That is, one exerts more effort when higher performance is paid with higher compensation. Laboratory experiments (Dickinson, 1999) and field experiments (Lazear, 2000; Banker et al., 1996) support this basic premise. Many topics, such as the principal agent theory, labor economics, and human resource management, are studied by considering this premise as a given.

However, in the field of social psychology, it has been pointed out that the monetary Corresponding author: Hiromasa Takahashi, Faculty of International Studies, Hiroshima City University, 3-4-1 Ozuka-Higashi, Asa-Minami, Hiroshima 731-3194, Japan. Tel:+ 81-82-8301525; E-mail: htaka@intl.hiroshima-cu.ac.jp. 
incentive does not necessarily facilitate one's effort and that, instead, it undermines efforts. The reason often cited for this behavior is the crowding out of intrinsic motivation by monetary motivation (Deci, 1975; Frey and Jegen, 2001; Frey and Oberholzer-Gee, 1997; Gneezy et al., 2011). The intrinsic motivation is the motivation unrelated to extrinsic monetary motivation, such as the pleasure of performing the activity, or the gratification achieved when one feels that s/he has helped others or society as a whole. Monetary incentive may undermine the intrinsic motivation. For example, Fehr and Gächter (2002) and Gneezy and Rustichini (2000a) showed that the monetary incentives undermine pro-social behavior. ${ }^{1}$

In the context of tasks, if the crowding out effect is greater than the effect of promotion of one's effort due to the monetary compensation provided, monetary compensation undermines one's effort or degrades performance. Deci (1971) conducted experiments consisting of three stages, and in all stages, participants worked on puzzles. In the first and last stages, participants performed without pay and in the second stage, they were paid according to their performance. Deci (1971) showed that participants exerted greater effort in the second stage than in the first and third stages. Especially, they exerted lesser effort in the third stage than in the first stage. This suggests that the monetary compensation undermined the intrinsic motivation in the third stage.

Gneezy and Rustichini (2000b) found a U-shaped relationship between effort and magnitude of incentive, or performance-based, pay. That is, the participants with low incentive compensation schemes performed worse in an IQ test than the participants in the scheme with a high incentive. However, the participants with low incentive schemes performed worse than the participants in the no payment scheme did. This result suggests that low monetary incentives help to crowd out the intrinsic motivation.

Pokorny (2008) reported an inverse U-shaped relationship between effort and magnitude of incentive pay. Level of effort increases in proportion to increase in monetary incentives at low levels. However, the level of effort decreases with respect to monetary incentives when it is higher than a certain level. This result contradicts the results of Gneezy and Rustichini (2000b). Pokorny (2008) explained the result of the reference-dependent preference and loss-aversion (Kahneman and Tversky, 1979; Tversky and Kahneman, 1991). ${ }^{2}$

\footnotetext{
${ }^{1}$ Lacetera and Macis (2010) and Mellström and Johannesson (2008) showed that the crowding out effect is different between males and females. It is also reported that the monetary incentive undermines pro-social behavior for reasons other than the crowding out effect. (Ariely et. al, 2009; Fuster and Meier, 2010)

2 Fehr and Goette (2007), Camerer et al. (1997), Crawford and Meng (2011) and Farber (2008) found that the higher wages reduced the effort or labor supply in their field experiments or field
} 
According to the Prospect Theory, people's preference depends on not only the achieved consumption or income levels, but also on some reference level or reference point (e.g., an average level, an expected level, or the level achieved in the preceding period). People interpret a level lower than the reference point as a loss and extremely dislike loss in the sense that decrease of utility when the achieved level is lower than the reference point by a given margin is larger than the increase in utility when the achieved level is higher than the reference point by the same margin.

In the case of the economic experiments and its rewards, the expected reward before the experiment starts may be a reference point for rewards. When show-up fee or incentives pay is small, the reward that a participant will get is more likely to fall below his reference point and this makes him work harder than when the show-up fee or incentive pay is large enough because of the fear of loss-aversion. In fact, the show-up fee in the experiment of Pokorny (2008) was much lower than that of Gneezy and Rustichini (2000b).In this case, the participants with the low incentive in Pokorny (2008) anticipated the lower reward than reference point and worked harder because of the fear of loss-aversion.

The relationship between effort and magnitude of incentives also depends on the level of interest the performer has towards the task. For example, Pascual-Ezama et al. (2013) found that those who have a high level of intrinsic motivation from the pleasure of doing the task itself, responded better to monetary incentives than those having a low level of intrinsic motivation towards the completion of the task.

Heyman and Ariely (2004) and Yam (2013) examined whether the relationship between effort and the magnitude of compensation differs according to whether it is based in the monetary market or the social market. ${ }^{3}$ Heyman and Ariely (2004) found that the larger the compensation in the monetary market, the harder one works; however, effort is not sensitive to the magnitude of compensation in the social market. Furthermore, they found that low payment in the monetary market decreases performance as compared to performance in the social market with no payment. Note that fixed pay is controlled in Heyman and Ariely (2004), in contrast to Gneezy and Rustichini (2000b) and Pokorny (2008). ${ }^{4}$ Their result showed that the standard economic theory asserting that effort is not sensitive to the magnitude of fixed pay is wrong.

studies. These results are consistent with the loss-aversion.

${ }^{3}$ In Heyman and Ariely (2004), they defined the case where monetary payments were used as a monetary market and the case where no monetary reward was involved or a gift reward was used as a social market.

${ }^{4}$ Squazzoni and Takács (2013) reported that fixed pay undermines the cooperative behavior. 
In this paper, we conducted subjective experiments in which the participants engaged in two types of real effort tasks with five different compensation schemes. One task involves clicking on circles and the other is to solve a series of kanji puzzles. We assume that the former task is boring, and has no intrinsic motivation derived from working on the task for its own sake, while the latter is interesting and has a large intrinsic motivation. The five compensation schemes were no payment, low incentive pay, high incentive pay, low fixed pay, and high fixed pay. From these experiments, we examine the relationship between exertion of effort and the magnitude and nature of compensation received.

The contribution of the current paper to the existing literature is two-fold. First, since compensation schemes applied in the previous studies were different (e.g., fixed pay in Heyman and Ariely (2004) vs. incentive pay in Gneezy and Rustichini (2000) and Pokorny (2008)), the results obtained from these studies were mixed. We apply both fixed pay and incentive pay compensation schemes to provide a systematic investigation of the relationship between levels of effort exerted and monetary incentive. Second, in our experiments, participants were asked to do both boring and interesting tasks. Thus, the influence of content of tasks performed on the relationship between effort levels and compensation schemes can also be examined. We believe that this experimental design can provide a fresh insight into the related literature.

The remainder of the paper is organized as follows. Section II describes the issues related to the experiment. The results of the experiment are presented in section III. Finally, section IV discusses the results and suggests several possible directions for future study.

\section{EXPERIMENT DESIGN}

We conducted five different treatments with different compensation schemes. Each treatment consisted of two tasks, clicking on circles and solving a series of kanji puzzles. Note that the contents of these two tasks were the same among treatments. In each treatment, participants were informed on how to click the circles and the compensation scheme for the task before performing the task. After completing the first task, they were informed on how to work on the kanji puzzle and the attached compensation scheme before being asked to solve the puzzles.

The procedure of the clicking circles task is as follows. After the task was started, a circle with a diameter of about 2 centimeters appeared in a random place on the computer screen. If a participant clicked inside the circle, s/he got one point and the 
circle would disappear. Simultaneously, a new circle would appear in a random place on the computer screen. If the participant clicked inside this circle, s/he got another point and the game would thus continue. This was repeated until time ran out. The points s/he got were indicated on the top of the computer screen. The task lasted 5 minutes and participants were encouraged to get as many points as they could. The clicking circles task (see Figure 1) is similar to the task of counting numbers in Pokorny (2008) or the task of dragging a digital ball in Heyman and Ariely (2004), in that they do not have any intrinsic motivation with regards to pleasure derived from working on the task itself. We measured the amount of effort exerted by the points obtained by the participant.

In the kanji puzzle task, participants were required to solve four kanji puzzles. Each puzzle was composed of the following; a solver makes three three-character idioms using nine blank boxes and ten given kanji characters. The time limit for solving each puzzle was fifteen minutes and would end when the puzzle is solved, the allotted time is lapsed, or when the solver clicks a give-up icon located at the bottom of the screen. The first three puzzles were relatively easy while the final puzzle was extremely difficult. The measure of effort was the length of time that participants spent in solving the final puzzle. A kanji puzzle (see Figure 2) is similar to the puzzle in Heyman and Ariely (2004), in which participants derived pleasure from solving it for its own sake.

The five compensation schemes were no payment, low incentive pay, high incentive pay, low fixed pay, and high fixed pay. In a no payment scheme, participants worked on both tasks without any pay. In the low and high fixed pay treatments, participants were paid $200 \mathrm{JPY}^{5}$ and $800 \mathrm{JPY}$, respectively, for the first task, and 300 JPY and $1200 \mathrm{JPY}$, respectively, for participation in the kanji puzzle task. In low incentive and high incentive payment schemes, participants were paid 0.5 JPY and 2 JPY, respectively, for every point scored in the first task and 100 JPY and 400 JPY, respectively, for every correct answer in the Kanji puzzle. ${ }^{6}$ Our experimental design is a "between participants design" for the factor of compensation scheme and a "within participants design" for the factor of real task.

Note that our "low incentive pay" is higher than the "very low incentive" of Gneezy and Rustichini (2000b) and Pokorny (2008). This is because Kansai University, where we conducted the experiment, requested us to ensure that the reward received by participants must not be lower than the minimum hourly wage. For the same reason, our "low fixed pay" is higher than the "low fixed pay" of Heyman and Ariely (2004).

\footnotetext{
${ }^{5}$ \$1 was about 100 JPY when the experiment was conducted.

${ }^{6}$ Note that we did not pay any show-up fees for participants in low incentive pay and high incentive pay treatments, unlike the experiments in Gneezy and Rustichini (2000b) and Pokorny (2008).
} 
Furthermore, our "high fixed pay" and "high incentive pay" are both higher than those of previous studies.

All five treatments were conducted at Kansai University in July 2013. 34, 24, 31, 29, and 27 undergraduate students participated in the no payment, low fixed pay, high fixed pay, low incentive pay, and high incentive pay treatments, respectively. Including payment, each treatment lasted for about forty minutes. ${ }^{7}$ Participants of the low incentive pay and high incentive pay treatments earned, on average, 523 JPY and 1,992 JPY, respectively.

\section{RESULTS}

The descriptive statistics of points in the first task and time before giving up in the last kanji puzzle in each treatment are provided in Tables 1 and 2, respectively. The visual representation of these results is presented in Figures $3-6$.

We will first discuss the results obtained in the first task under incentive pay schemes. From Table 1, average points in the first task in no payment, low incentive, and high incentive treatments were 413.7, 446.7, and 395.9, respectively. Figure 3 shows an inverse U-shape relationship between the points and the magnitude of incentives, which suggests that in comparison with no payment, a high incentive payment does not improve the level of effort exerted, although the low incentive pay does improve performance.

The second column of Table 3 reports the regression results of the first task, with the dependent variable being the points secured in the task. The independent variables are Low incentive (a dummy variable equals 1 if the subjects participated in the low incentive pay treatment and 0 otherwise), High incentive (a dummy variable equals 1 if the subjects participated in the high incentive pay treatment and 0 otherwise), Low fixed pay (a dummy variable equals 1 if the subjects participated in the low fixed pay treatment and 0 otherwise), and High fixed pay (a dummy variable equals 1 if the subjects participated in the high fixed pay treatment and 0 otherwise). As shown in the column, the subjects in the low incentive treatment performed significantly better than those in the no payment treatment did, whereas the subjects in the high incentive treatment did not perform significantly differently than those in the no payment treatment.

\footnotetext{
${ }^{7}$ To recruit participants, we used the online billboard of Kansai University, except for the no payment treatment. In no payment treatment, participants were students attending a class on elementary research methods. We informed them that their performance in the experiment was not related to their scores in the class.
} 
Considering the second task under incentive pay schemes, we first confirm the absence of bias in the participants' ability in solving kanji puzzles. The average accuracy rate in the first three puzzles was 99\% and the average time for solving these puzzles was about thirty seconds. There were no significant differences in these averages among the treatments. Only one participant solved the fourth puzzle. ${ }^{8}$ These results indicate the absence of bias in participants' ability in solving kanji puzzles.

From Table 2, the average length of time before giving up in the last kanji puzzle in no payment, low incentive, and high incentive treatments were 219.8, 413.4, and 724.9 seconds, respectively. As shown in Figure 4, it suggests that the higher the incentive, the more effort one exerts, which is consistent with the prediction of standard economic theory.

The rightmost column of Table 3 reports the Tobit regression results of the kanji puzzle. The dependent variable is the time before giving up in the last kanji puzzle. The independent variables are the same as in the regression of the first task. As shown in the column, the subjects with low and high incentive pay treatments spend significantly more time on trying to solve the puzzle than those in the no payment treatment. Furthermore, an F-test $(\mathrm{p}<0.01)$ indicates that these coefficients are significantly different. That is, the more incentive provided as compensation, the longer the subjects work through the most difficult puzzle.

We found that there are different effects of incentivized pay between the two tasks. This suggests that the more incentive pay is given, the more effort one exerts when one engages in a task with high intrinsic motivation. Our result is consistent with that of Pascual-Ezama et al. (2013).

We now turn our attention to the effect of fixed pay schemes on performance in the first task. From Table 1, average points in the first task in no payment, low fixed pay, and high fixed pay treatments were 413.7, 428.0, and 390.8, respectively. As shown in Figure 5, it seems that the relationship between the points and the magnitude of fixed pay also follows an inverse U-shaped curve, as in the case of incentive-based compensation. However, as indicated by the regression results in the second column of Table 3, points obtained in the first task with low fixed pay treatment were not significantly different from those in the no payment treatment, while points obtained in the high fixed pay treatment were significantly lower than those in both no payment and low fixed pay treatments. This result is, on the one hand, consistent with the prediction of standard economic theory in that fixed pay does not influence the level of effort exerted; however, on the other hand, it also suggests that a high fixed pay can lower

8 The participant who solved the final puzzle participated in a no pay treatment. 
participants’ performances.

Examining the performance in the second task under fixed pay schemes, we can see from Table 2 that the average length of time before giving up in the last kanji puzzle in no payment, low fixed pay, and high fixed pay treatments were 219.8, 224.0, and 194.4 seconds, respectively. As shown in Figure 6, it seems that there are almost no differences in the average time spent among the three treatments. This is confirmed by the Tobit regression results presented in the right most column of Table 3. As indicated, the coefficients of both Low fixed pay and High fixed pay are not significantly different, suggesting that the effort of solving the last kanji puzzle is not affected by the magnitude of fixed pay.

\section{CONCLUSION}

In this paper, we examined the influence of difference in compensation schemes on effort on two real effort tasks. The first task was assumed to be boring and thus have no intrinsic motivation, with the second task being assumed to be interesting, and thus providing intrinsic motivation.

Results regarding the relationship between effort and the magnitude of incentive pay are as follows. (1) In the case of the first task, level of effort is higher in the low incentive pay treatment than in the no payment treatment; however, levels of effort are lower in the high incentive pay than in the low incentive pay. In other words, the relationship between effort and magnitude of incentive pay is in the shape of an inverted U. This result is consistent with the result of Pokorny (2008) rather than that of Gneezy and Rustichini (2000b). Though our "low incentive pay" was larger than the "very low incentive" of Pokorny (2008), there were no show-up fees in our treatment unlike the experiment of Pokorny (2008). Therefore, the participants might think that the reward they would get was more likely to fall below the reference point and this makes them work harder because of loss-aversion. In contrast, (2) in the case of the kanji puzzle, the higher the incentive pay, the more effort one exerts. This result is consistent with standard economic theory. Results (1) and (2) suggest that one exerts effort for a task without intrinsic motivation due to the fear of loss-aversion, whereas he does not do so for a task with intrinsic motivation.

Results for the relationship between effort and magnitude of fixed pay are as follows. (3) In the case of the first task, level of effort was lower in the high fixed pay than in the no payment and low fixed pay schemes. This result does not necessarily contradict the result of Heyman and Ariely (2004) because our "low fixed pay" is larger than their 
"low condition," instead the result is a new finding because our "high fixed pay" is much larger than their "high condition." We think the reason for this result is that the high fixed pay per se possibly signals to the participants the difficulty of the first task (Benabou and Tirole, 2003). In other words, the participants perceived the task to be very difficult when given a high fixed pay. Furthermore, the rewards do not increase even if they perform better. Hence, they do not work as hard. The last result is (4) in the case of the kanji puzzle, the difference in levels of effort among no payment, low fixed pay, and high fixed pay treatments were not observed. This result is consistent with the standard economic theory.

Summing up the above results, we suggest that to maximize exertion of one's effort for a task without intrinsic motivation, we should pay a performance-related amount but should not pay too much, while to maximize effort for a task with intrinsic motivation, pay a performance-related amount as high as possible.

\section{ACKNOWLEDGEMENTS}

Financial support from the Japanese Ministry of Education, Culture, Sports, Science and Technology through Grand-in-aid for Scientific Research (C) 25380234 is gratefully acknowledged. All of the views expressed in this paper and any errors are the sole responsibility of the authors.

\section{APPENDIX: EXPERIMENTAL INSTRUCTIONS}

\section{A.1. For clicking the circles task in the high incentive treatment}

\section{Procedure of the experiment}

We will conduct two experiments. First, we explain the procedure of the first experiment. Please read carefully and make sure you understand.

(1) Please click the start button at the center of the screen when the experimenter cues.

(2) Click on the inside of the circle appearing at random place on the screen.

(3) If you click the circle correctly, the score on the screen will rise.

(4) The time limit for this task is 300 seconds.

(5) Please click as many as you can in the allotted time limit.

\section{Payoff}

Your payoff for this experiment is calculated as follows. 


\section{Scores $\times \quad$ 2JPY}

A.2. For kanji puzzle solving task in the high incentive treatment

\section{Procedure of the experiment}

(1) Please click the start button at the center of the screen when the experimenter cues.

(2) Nine blank boxes appear on the top of the screen and ten kanji characters appear at the bottom of the screen.

(3) Please drag the kanji characters to the boxes to make three three-character idioms using nine kanji characters from the given ten kanji characters.

(4) If you make three three-character idioms correctly, the next problem will start.

(5) Click the GIVE UP icon on the lower right hand side of the screen if you cannot solve the problem and want to give up. Then the next problem will start.

(6) The next problem will also start if you cannot solve the puzzle within the time limit.

(7) The kanji characters return to the original position if you push the RESET button at the lower right hand side of the screen.

(8) There are four problems in total.

(9) The time limit for each problem is 15 minutes and the time remaining is indicated on the top of the screen.

\section{Payoff}

Your payoff for this experiment is calculated as follows.

\section{The number of correct answers $\times \quad 400 J P Y$}

\section{REFERENCES}

Ariely, D., Bracha, A. and Meier, S. (2009). 'Doing good or doing well? Image motivation and monetary incentives in behaving prosocially', The American Economic Review, 99 (1), pp. 544-555.

Ariely, D., Gneezy, U., Loewenstein, G. and Mazar, N. (2009). 'Large stakes and big mistakes', The Review of Economic Studies, 76(2), pp. 451-469.

Benabou, R. and Tirole, J. (2003). 'Intrinsic and extrinsic motivation', The Review of Economic Studies, 70(3), pp. 489-520. 
Banker, R. D., Lee, S. Y. and Potter, G. (1996). 'A field study of the impact of a performance-based incentive plan', Journal of Accounting and Economics, 21(2), pp. 195-226.

Camerer, C., Babcock, L., Loewenstein, G. and Thaler, R. (1997). 'Labor supply of New York city cab drivers: One day at a time', The Quarterly Journal of Economics, 112(2), pp. 407-441.

Crawford, V. P. and Meng, J. (2011). 'New York city cab drivers' labor supply revisited: Reference-dependent preferences with rational expectations targets for hours and income’, The American Economic Review, 101(5), pp. 1912-1932.

Deci, E. L. (1971). 'Effects of externally mediated rewards on intrinsic motivation', Journal of personality and Social Psychology, 18(1), pp. 105.

Deci, E.L. (1975). Intrinsic motivation, New York: Plenum Press.

Dickinson, D.L. (1999). 'An experimental examination of labor supply and work intensities', Journal of Labor Economics, 17(4), pp. 638-670.

Farber, H. S. (2008). 'Reference-dependent preferences and labor supply: The case of New York city taxi drivers’, American Economic Review, 98(2), pp. 1069-1082.

Fehr, E. and Gächter, S. (2002). 'Do incentive contracts undermine voluntary cooperation? '.

Fehr, E. and Goette, L. (2007). 'Do workers work more if wages are high? Evidence from a randomized field experiment', The American Economic Review, 97(1), pp. 298-317.

Frey, B. S. (1994). 'How intrinsic motivation is crowded out and in', Rationality and Society, 6(3), pp. 334-352.

Frey, B. S. and Jegen, R. (2001). 'Motivation crowding theory', Journal of economic surveys, 15(5), pp. 589-611.

Frey, B. S. and Oberholzer-Gee, F. (1997). 'The cost of price incentives: An empirical analysis of motivation crowding-out', The American economic review, 87(4), pp. 746-755.

Fuster, A. and Meier, S. (2010). 'Another hidden cost of incentives: The detrimental effect on norm enforcement', Management Science, 56(1), pp. 57-70.

Gneezy, U., Meier, S. and Rey-Biel, P. (2011). 'When and why incentives (don't) work to modify behavior’, The Journal of Economic Perspectives, 25(4), pp. 191-209.

Gneezy, U. and Rustichini, A. (2000a). 'Fine is a price', a. J. Legal Stud., 29(1), pp. 117.

Gneezy, U. and Rustichini, A. (2000b). 'Pay enough or don't pay at all', The Quarterly Journal of Economics, 115(3), pp. 791-810. 
Heyman, J. and Ariely, D. (2004). 'Effort for payment: A tale of two markets', Psychological Science, 15(11), pp. 787-793.

Kahneman, D. and Tversky, A. (1979). 'Prospect theory: An analysis of decision under risk', Econometrica: Journal of the Econometric Society, 47(2), pp. 263-291.

Lacetera, N. and Macis, M. (2010). 'Do all material incentives for pro-social activities backfire? The response to cash and non-cash incentives for blood donations', Journal of Economic Psychology, 31(4), pp. 738-748.

Lazear, E. P. (2000). 'Performance pay and productivity', American Economic Review, 90(5), pp. 1346-1391.

Mellström, C. and Johannesson, M. (2008). 'Crowding out in blood donation: was Titmuss right? ', Journal of the European Economic Association, 6(4), pp. 845-863.

Pascual-Ezama, D., Prelec, D. and Dunfield, D. (2013). 'Motivation, money, prestige and cheats', Journal of Economic Behavior \& Organization, 93(5), pp. 367-373.

Pokorny, K. (2008). 'Pay-but do not pay too much: An experimental study on the impact of incentives', Journal of Economic Behavior and Organization, 66(2), pp. 251-264.

Squazzoni, F., Bravo, G. and Takács, K. (2013). 'Does incentive provision increase the quality of peer review? An experimental study', Research Policy, 42(1), pp. 287-294.

Tversky, A. and Kahneman, D. (1991). 'Loss aversion in riskless choice: A reference-dependent model', The Quarterly Journal of Economics, 106(4), pp. 10391061.

Yam, K. C. (2013). 'Experimental manipulations to reduce the negative effects of money', Journal of Applied Social Psychology, 43(5), pp. 1104-1109. 


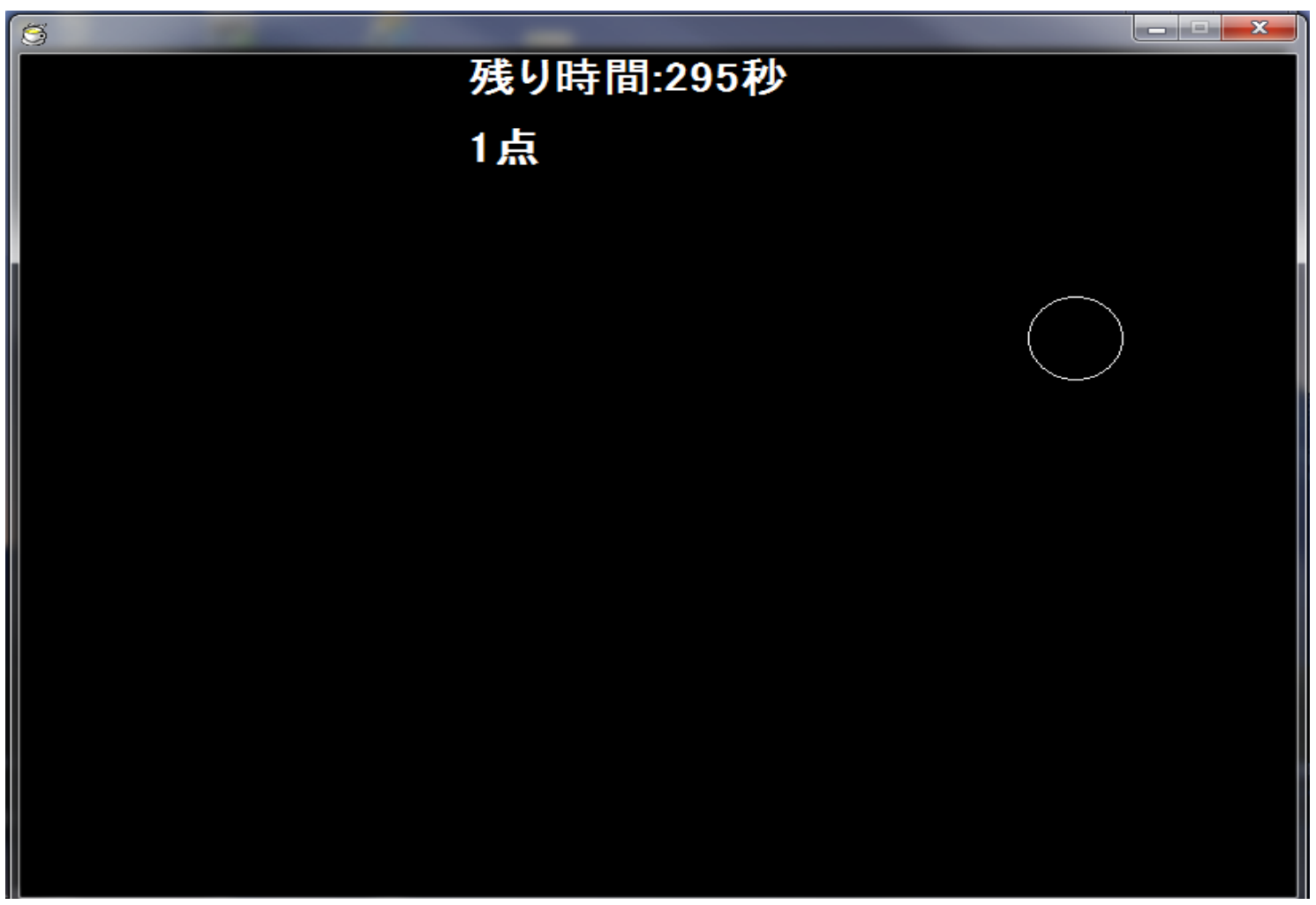

Figure 1. An image of clicking circles task

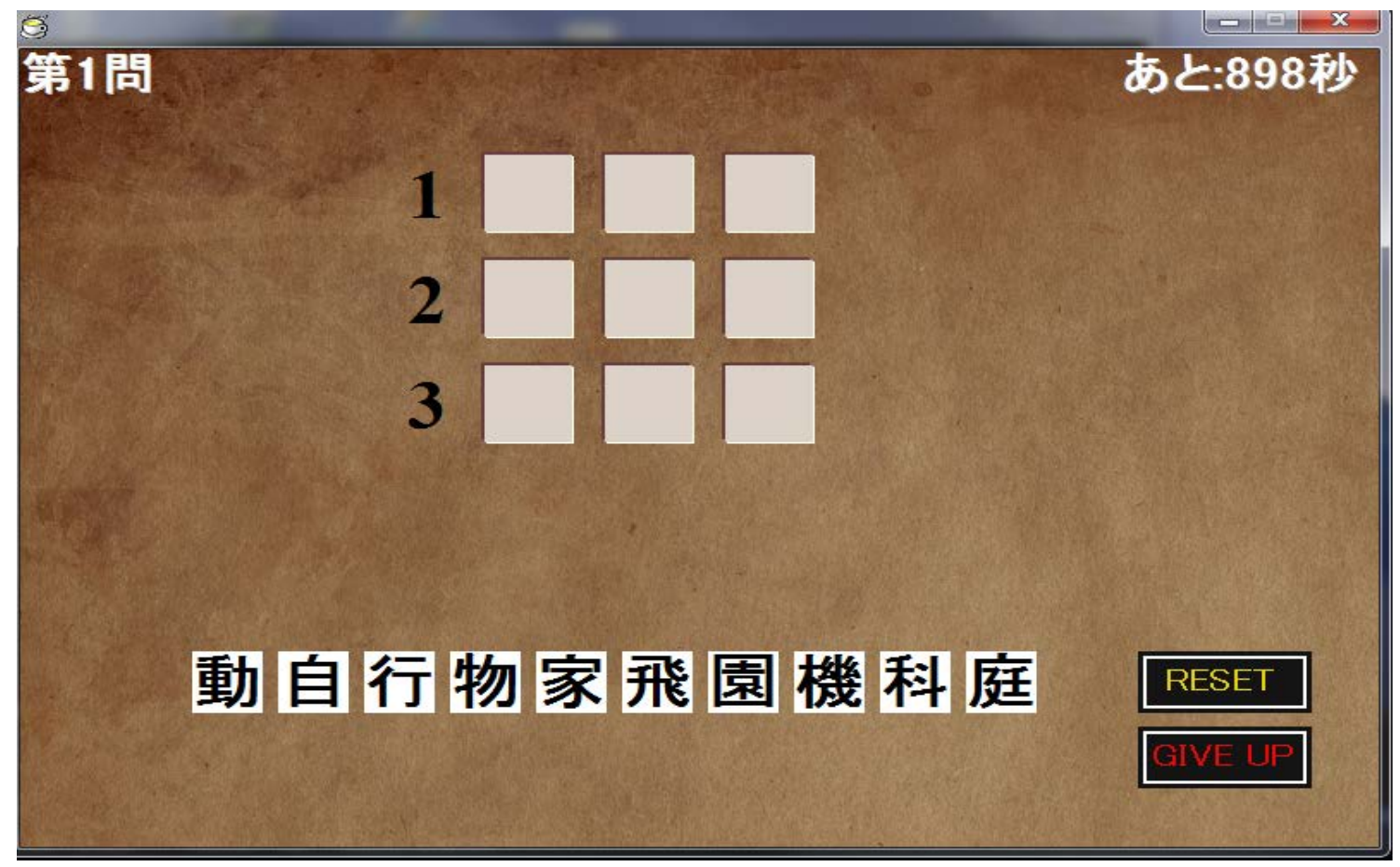

Figure 2. An image of the kanji puzzle 


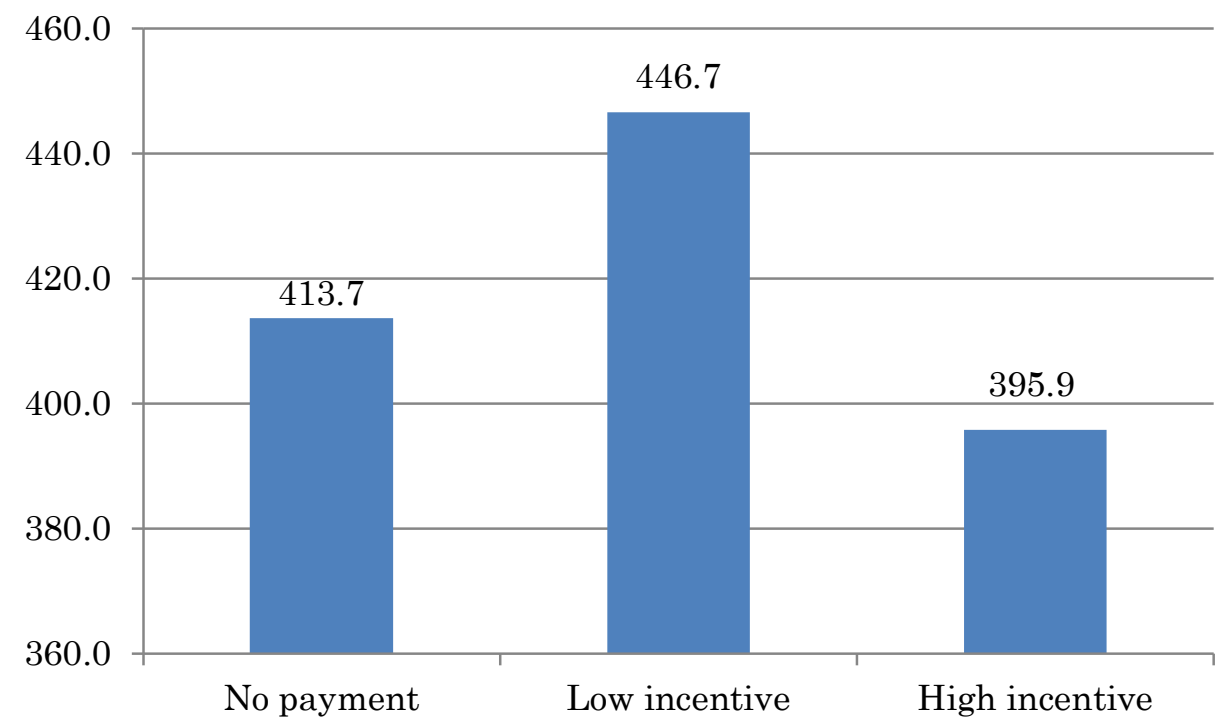

Figure3. Average points of clicking circles task (incentive compensation)

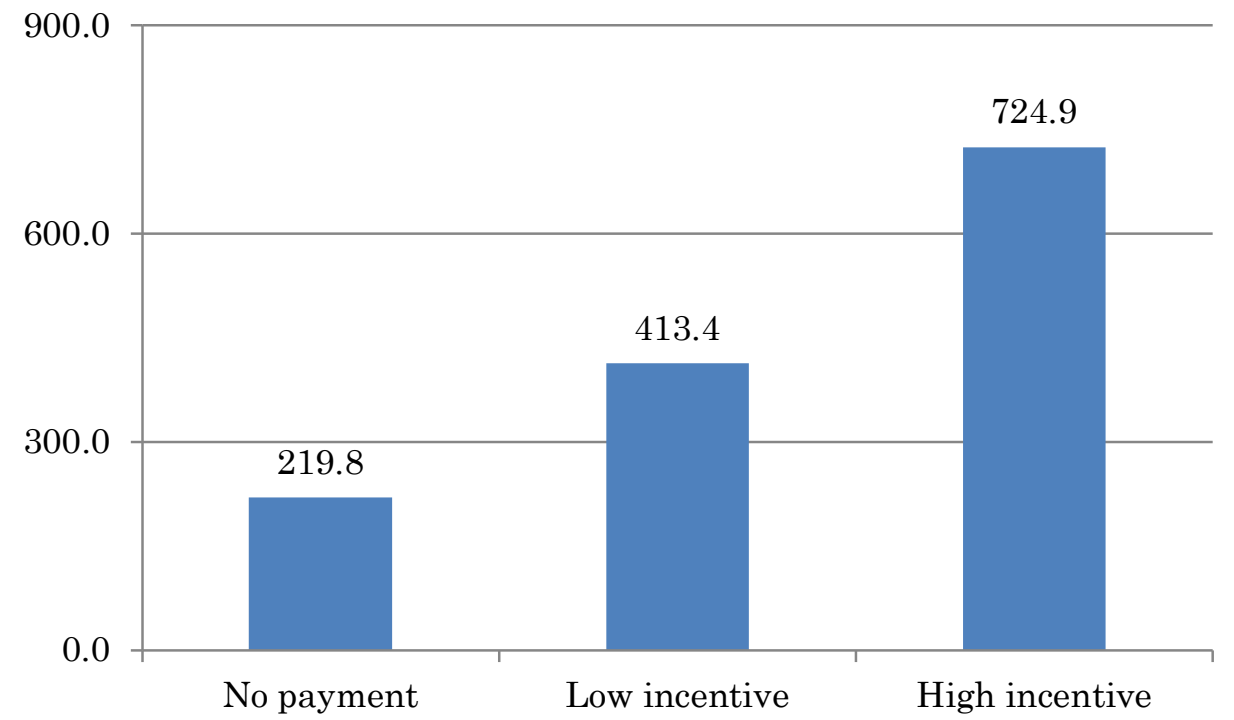

Figure 4. Average time before giving up the last kanji puzzle (incentive compensation) 


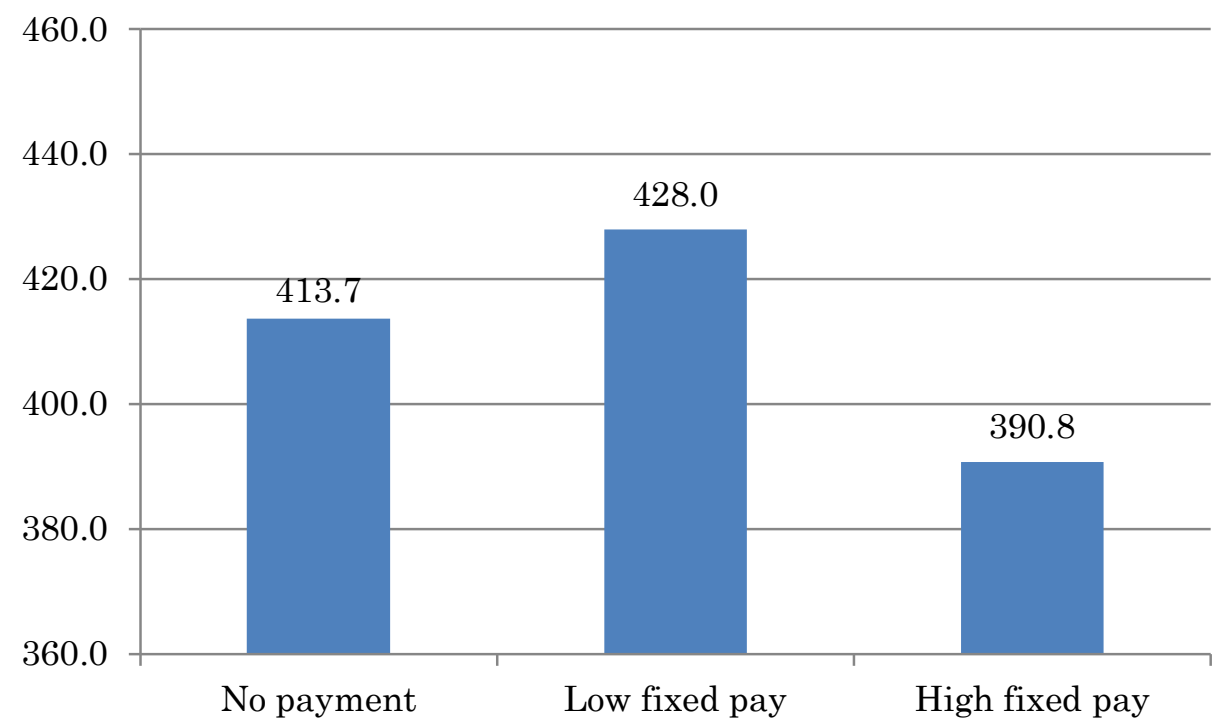

Figure 5. Average points of clicking circles task (fixed pay)

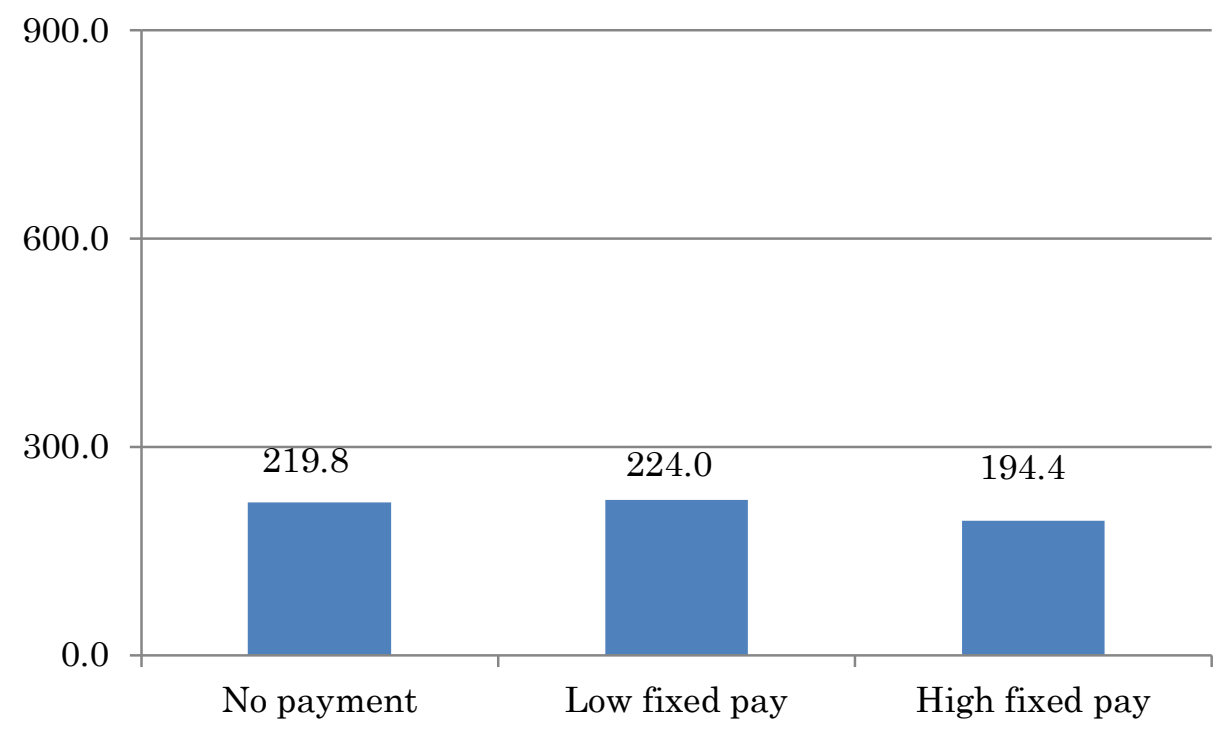

Figure 6. Average time before giving up the last kanji puzzle (fixed pay) 
Table 1. Descriptive statistics of points of clicking circles

\begin{tabular}{lccccc}
\hline \multicolumn{1}{c}{ Condition } & Mean & Standard deviation & Max & Min & N \\
\hline No payment & 413.7 & 48.6 & 480 & 295 & 34 \\
Low incentive pay & 446.7 & 50.1 & 525 & 287 & 29 \\
High incentive pay & 395.9 & 26.9 & 452 & 346 & 27 \\
Low fixed pay & 428.0 & 40.9 & 476 & 271 & 24 \\
High fixed pay & 390.8 & 37.2 & 451 & 312 & 30 \\
\hline
\end{tabular}

Table 2. Descriptive statistics of time length before giving up the last kanji puzzle

\begin{tabular}{lccccc}
\hline \multicolumn{1}{c}{ Condition } & Mean & Standard deviation & Max & Min & N \\
\hline No payment & 219.8 & 204.3 & 879 & 20 & 33 \\
Low incentive pay & 413.4 & 341.5 & 900 & 23 & 29 \\
High incentive pay & 724.9 & 267.0 & 900 & 105 & 26 \\
Low fixed pay & 224.0 & 179.6 & 770 & 23 & 23 \\
High fixed pay & 194.4 & 152.3 & 767 & 12 & 31 \\
\hline
\end{tabular}

Table 3. Regression results

\begin{tabular}{lcc}
\hline & Click circles & Kanji puzzle \\
\hline Constant & $413.677^{* *}$ & $219.758^{* *}$ \\
Low incentive & $(8.360)$ & $(35.153)$ \\
& $33.013^{* *}$ & $211.925^{* *}$ \\
High incentive & $(12.515)$ & $(78.005)$ \\
& -17.825 & $614.102^{* *}$ \\
Low fixed pay & $(9.831)$ & $(85.773)$ \\
& 14.324 & 4.286 \\
High fixed pay & $(11.788)$ & $(50.864)$ \\
& $-22.876^{*}$ & -25.338 \\
\end{tabular}

Notes: The regression of kanji puzzle is a Tobit regression whose censoring points are 0 and 900 . Robust standard errors are in parentheses. ${ }^{*} p<0.05,{ }^{* *} p<0.01$. 